\title{
Advanced methodology for risk and vulnerability assessment of interdependency of critical infrastructure in respect to urban floods
}

\author{
Damien Serre ${ }^{1}$ \\ ${ }^{1}$ UMR ESPACE 7300 CNRS, Université d'Avignon et des Pays du Vaucluse, Case 19, 74 rue Louis Pasteur, 84029 Avignon Cedex, France
}

\begin{abstract}
The behaviour of the urban network infrastructures, and their interactions during flood events, will have direct and indirect consequences on the flood risk level in the built environment. By urban network infrastructures we include all the urban technical networks like transportation, energy, water supply, waste water, telecommunication... able to spread the flood risk in cities, qualified as critical infrastructures due to their major roles for modern living standards. From history, most of cities in the world have been built close to coast lines or to river to beneficiate this means of communication and trade. Step by step, to avoid being flooded, defences like levees have been built. The capacity of the levees to retain the floods depends on their conditions, their performance level and the capacity of the authorities to well maintain these infrastructures. But recent history shows the limits of a flood risk management strategy focused on protection, leading to levee breaks these last decades. Then, in case of levee break, cities will be flooded. The urban technical networks, due to the way they have been designed, their conditions and their locations in the city, will play a major role in the diffusion of the flood extent. Also, the flood risk will have consequences in some not flooded neighbourhoods due to networks collapses and complex interdependencies. This article describes some methods to design spatial decision support systems in that context.
\end{abstract}

\section{Introduction}

Flood is one of the major natural hazards that has caused loss of lives, significant economic damage, pollution on the nature and the built environment, loss of cultural heritages, and even caused community disorder and health problems. Global emerging flood emergency events caused by climate change in combination with other types of natural or constructional disasters and community development based on the traditional concepts for planning, design and operation call for better understanding of the emerging external driving factors for changes and internal failures of the physical system networks and the interdependency between the major and the induced disasters and the different types of critical infrastructure. It calls for suitable analytical approaches to identify the potential hazards and vulnerabilities for decision makers in different levels.

Approach for risk analysis and assessment has been existing for several decades and has been applied globally in different areas (Altman, 1970; Amendola, 1989; CSA, 1991; NTS, 1998). The traditional approach for risk assessment is expert estimation based on their experience (e.g. DSB, 1994; AGO, 2006). Software tools have been developed (e.g. Vatn, 2007), however they do not increase the assessment accuracy, indeed the uncertainty

\footnotetext{
a Corresponding author: Damien.serre@,univ-avignon.fr
}

remains high because of the coarse nature of the input data and inaccurate methods for assessment (Nie et al, 2009). Recently, more and more risk and vulnerability assessment studies have been implemented based on numerical models, which are able to provide more accurate results (e.g. Cancado et al., 2011; Zhou et al, 2011; Nie et al., 2012). The users can usually decide to apply whether a simple approach or a complicated/advanced model, according to their requirements for analysis results, and also depending on available data and resources. However, the traditional risk analysis methods do not take into account the interdependence between the analytical system and the infrastructures, and in particular the critical infrastructures (CIs).

At the core of every list of CIs are the large-scale technical grids of energy, water, communication and transportation (De Bruijn \& Van Eeten, 2007). Evaluating network infrastructures for potential vulnerabilities is thus an important component of strategic planning, particularly in the context of managing and mitigating service disruptions (Matisziw et al. 2008). For instance, the reliability and rapid restoration of the electric grid in particular is necessary to support the needs of the population within the disaster area effectively (Winkler et al., 2010). 
In fact, for a critical infrastructure, getting dysfunctional is a phenomenon that transcends by far the failure of any, even major, single component. The often incomprehensible cause of system crash stems from the inherent features of the critical infrastructures: they are multicomponent systems, prone to cooperative behavior, and typically responding in a non-linear fashion to stimuli and perturbations. There is an urgent need for appropriate and credible solutions to address such systems in the areas of vulnerability and risk assessment, as a substantial, and indeed critical, component of the contemporary policy making.

Modelling interdependencies between these infrastructures is a relatively new field of research. From a methodological point of view, most methods concerning interdependencies modelling propose mathematical modelling through network theory (Ouyang et al., 2009; Eusgeld, et al. 2009). Graphs are implemented to represent the topology of the infrastructures and their interdependencies. In addition to network theory, Lewis (2006) uses principles of logic, probability, and cost minimization. Others propose the elicitation of expert judgment (Parks \& Rogers, 2009; Ezell, 2007) and qualitative assessments (Baker, 2005; Haimes \& Longstaff, 2002). Safety methods can also be applied to study vulnerability of critical infrastructures and their interdependencies (Lhomme et al., 2011). However, new tools are needed to implement these methods in order to finally help the design of efficient critical infrastructures protection plan. In the first part we are critical infrastructure issues in terms of flood risk management, the we are describing the methods used to analyse their interdependencies. Finally we are applying the model at the neighbourhood scale.

\section{Flood risk and critical infrastructures}

Defining the expression "critical infrastructure" is a challenging task, as no international consensus exists on the topic. Etymologically, the term "critical" comes from the latine criticus, itself originating from the Ancient Greek кpıєıкós (kritikos), "able to judgement, to wisdom". The word can also be linked to кpí or also, derived from the verb krinein ("to separate", "to choose", "to decide", "to sieve"). The signification of the word has then evolved throughout the centuries. As for the term "infrastructure", the word is a combination of the Latin prefix "infra", meaning "below", and "structure". Some sources trace the first origins of the word to the military field (Oxford English Dictionary), and further imported to English from the French, where it means subgrade, the native material underneath a constructed pavement or railway.

Nowadays, an infrastructure is often described as a set of basic facilities, services, and installations that are necessary for the functioning of a community or society. The detailed list of actual objects that should be included within this context varies, it can include for example transportation and communications systems, water and power supplies, employment centers, medical facilities, and public institutions, including schools, post offices, and prisons. They are qualified critical because a disruption would threaten the security, economy, public health, safety, and way of life of a community or society. Thus, a critical infrastructure (CI) can be defined as an array of assets and systems that, if disrupted, would threaten national security, economy, public health and safety, and way of life (McNally et al, 2007).

This is a very broad definition with no accurate meanings. Indeed, critical infrastructure systems of-ten cross geographic, political, cultural, and organizational boundaries and may be either built, natural, or virtual (Pederson et al., 2006). Built critical infrastructure includes energy; water and wastewater treatment, distribution, and collection; transportation; and communications systems. Natural critical infrastructure systems include lakes, rivers, and streams that are used for navigation, water supply, or flood water storage, as well as coastal wetlands that provide a buffer for storm surges. Virtual critical infrastructure includes cyber, electronic, and information systems (Pederson et al., 2006). Nevertheless, there is no common list and each country has de-fined its own list.

Despite no common list exists, many attempts to qualify critical infrastructures have been performed. According to LaPorte (2007), the specific characteristics of these systems make them: Tightly coupled technically, with complex organizational and management imperatives prompted by operating requirements designed into the system; un-substitutable services to the public; With few competing networks delivering the same service; The objects of public anxiety about the possible widespread loss of capacity and interrupted service; The source of alarm about the consequences of serious operating failures to users and outsiders, and subsequent public expressions of fear (De Bruijn \& Van Eeten, 2007).

The definition of what critical infrastructure actually means is constantly evolving, because of its dependence on the historical, political and cultural contexts. The limitations in finding a consensus are highlighted by the variety of definitions given by various societies, as well as by the fact that important areas of the world (namely South America, Africa or Asia) do not exhibit important literature on the topic, while others, as the United States, show dense information. This fact emphasizes the cultural connotation of the concept. When considering the investment policies, the trend towards discriminatory policies is obvious, which highlights the fact that suspicion towards foreign entities is a concern when dealing with critical infrastructure. Although this suspicion is probably less relevant when the threat on critical infrastructure is of natural origin as a flood, the existence of suspicion still suggests one additional possible reason making it difficult to define critical infrastructure in a universal way. Nevertheless, whatever the exact definition, it remains that as civilizations have become more complex and engineered solutions more sophisticated, the public has come to rely on the integrity of built projects for safety and well-being. When those projects fail, the consequences have become commensurately more devastating, calling for subsequently complex methods to assess their 
vulnerability and the risk to which they are submitted. Notable infrastructure disasters that have occurred over the past century serve as a stark reminder of the importance of critical infrastructure to public safety, health, and welfare.

Through direct connectivity, policies and procedures, or geospatial proximity, most critical infrastructure systems interact. These interactions often create complex relationships, dependencies, and interdependencies that cross infrastructure boundaries. The modelling and analysis of interdependencies between critical infrastructure elements is a relatively new and very important field of study. Thus, in the past few years, many researchers have concentrated on the modeling and analysis of interdependent infrastructures. As a result, many methods have been proposed to facilitate such analysis, providing different interpretations of infrastructure vulnerability.

The infrastructures are interconnected and interdependent on multiple levels. To understand the cascading failures among infrastructure systems under random incidents, manmade attacks and natural hazards, many researchers have proposed different methods for modelling and simulation of interdependent infrastructure systems. Notable examples include: Agent Based Methods; Inoperability Input-output Methods; System Dynamics Methods; Network or Graph Based Methods; Data Driven Methods (Ouyang et al., 2011).

Identifying, understanding, and analyzing such interdependencies are significant challenges. These challenges are greatly magnified by the breadth and complexity of critical infrastructures, and by a broad range of interrelated factors and system conditions. These ones are often represented and described in terms of six dimensions (Rinaldi et al., 2004). These six dimensions include: the technical, economic, business, social/political, legal/regulatory, public policy, health and safety, and security concerns that affect infrastructure operations.

Interdependent infrastructures also display a wide range of spatial, temporal, operational, and organizational characteristics, which can affect their ability to adapt to changing system conditions. And finally, interdependencies and the resultant infrastructure topologies can create subtle interactions and feedback mechanisms that often lead to unintended behaviours and consequences during disruptions (Rinaldi et al., 2004).

\section{Methods and tools}

\subsection{A resilience concept based approach}

Derived from ecology, the concept of resilience is firstly defined as "the measure of the persistence of systems and of their ability to absorb change and disturbance and still maintain the same relationships between populations or state variables" (Holling, 1973). Nowadays this concept is use in many others disciplines (like physics, psychology, economy, environment...). But for risk management this concept is relatively new, especially concerning natural hazard. We study number of others disciplines in order to well understand resilience concept and to define this concept concerning urban risk management. It appears that resilience is usually used in the continuity of existing terms in these various disciplines. The abundance of definitions of disaster resilience and the fact that this concept is shared by many disciplines makes it difficult to have a common definition. Disaster management has typically focused on analyzing the hazard. Yet, climate related risks have been increasing in frequency and severity, so researchers and few decision makers recognize the need to not only analyze the hazard but also to try to prepare the plan B like it seems the concept of resilience can bring. That is why disaster management has been moving away from solely emergency response, initiated during and after a flood event, toward mitigation and preparedness, initiated before an event, in order to reduce impacts more effectively. So, in the current discussion on flood resilient cities a strong emphasis is placed on improving the flood performance of buildings. Yet, the city has to be considered as an entity with different systems and vital functions and not merely as a set of concrete buildings if we want to design fully resilient cities.

\subsection{Objectives}

Here, there is a huge issue because city is a complex object. Nowadays, the principle is to study the city like a system, especially like a complex one: such systems are not fully predictable, due to the inherent uncertainty in how these systems evolve. As illustrated in the literature a city appears as a set of components interconnected by networks with some critical infrastructures (Serre, 2011). Evaluating critical infrastructure network interdependencies for potential vulnerabilities is an important component of a strategic planning, particularly in the context of managing and mitigating service disruptions. Yet, multiple networks that innervate cities are particularly sensitive to risks, through their structures and geographic constraints. There is a need to understand how networked systems are resilient because societal functions are highly dependent on networked systems and the operability of these systems can be vulnerable to disasters.

\subsection{The DS3 model}

In our research, the concept of resilience is defined as "the ability of a system to absorb a disturbance and recover its functions following the disturbance" (Lhomme et al., 2010). Indeed, in the resilience concept, the object studied is a system. Assuming that the city can be considered as a system, the resilience definition can be transposed to the urban context as: "the ability of a city to operate in a degraded mode and recover its functions while some urban components remain disrupted" (Lhomme et al., 2010). Serre (2011), according to its urban resilience definition, has developed a conceptual model to analyze the resilience of urban networks: the DS3 (Spatial Decision Support System) model. In this model, three capacities have been defined as essential to study the resilience of urban networks (Serre, 2011): resistance, absorption and recovery (Fig. 1). This 
approach is based on the performance of the urban interconnected systems analysis at the city level and focuses on a physical urban dimension, particularly on technical aspects (Balsells et al., 2013). networks are needed (location, condition, exposure...). This type of information is referred to as spatial information, and when visualized, we can see relationships, patterns, and trends that may not otherwise be apparent. It is well known that Urban Resilience $=$ maintening urban functions during the event and recove

GIS (Geographic Information Systems) can be used to recover the spatial component of risk and it is clear that risk assessments have an important spatial component. For instance, to better respond to post disaster activities, GIS technology provides a logical tool for integrating the necessary information and contributing to preparedness, rescue, relief, recovery and reconstruction efforts. GIS is seen as a necessary tool in the area of emergency response. But now resilience requires looking

Figure 1. DS3 model representation, including urban resilience objectives and associated disciplines

The resistance capacity of a system begins with a system damage analysis. Resistance capacity is considered as the starting point for any resilience analysis. It is necessary to know the potential damages so that the failure which the system must be able to absorb and from which it needs to recover. On the other hand, the absorption capacity is a function that involves the assimilation of a disturbance that needs to accommodate the disturbance rather than to oppose it, thereby introducing the disturbance in the system's performance. The study of the absorption capacity refers to the alternatives that can be offered by the system following the failure of one or more of its components (Lhomme et al, 2011). This requires studying its redundancy properties. Indeed, the redundancy is defined as one of the properties characterizing the resilience of different systems (Clarke et al., 1998), (Bruneau et al., 2003) and (Ahern, 2011). Usually, if a component of a system ceases to work (it does not achieve its function), a redundant system can mitigate this failure with an alternative (Serre, 2011). Finally, the recovery capacity is the most representative of the resilience concept (Serre et al., 2013). Recovery does not mean returning to a previous state, but rather a functional recovery of the system. The recovery leads the system to recover a state, a structure or a property.

\subsection{A Spatial Decision Support System (SDSS) for critical infrastructure interdependencies modelling}

The methodology presented above allows producing networks failure scenarios taking into account networks interdependencies. In our research, information about housing, companies, infrastructures, hazards and beyond lonely emergency response in order to optimize recovery after a flood event thanks to preparedness and resilience assessment. That is

Geographic

Information

Sciences

why a GIS prototype has been developed in order to implement the developed methods and the three capacities relevant for a future urban resilient conception design (Fig. 2). 


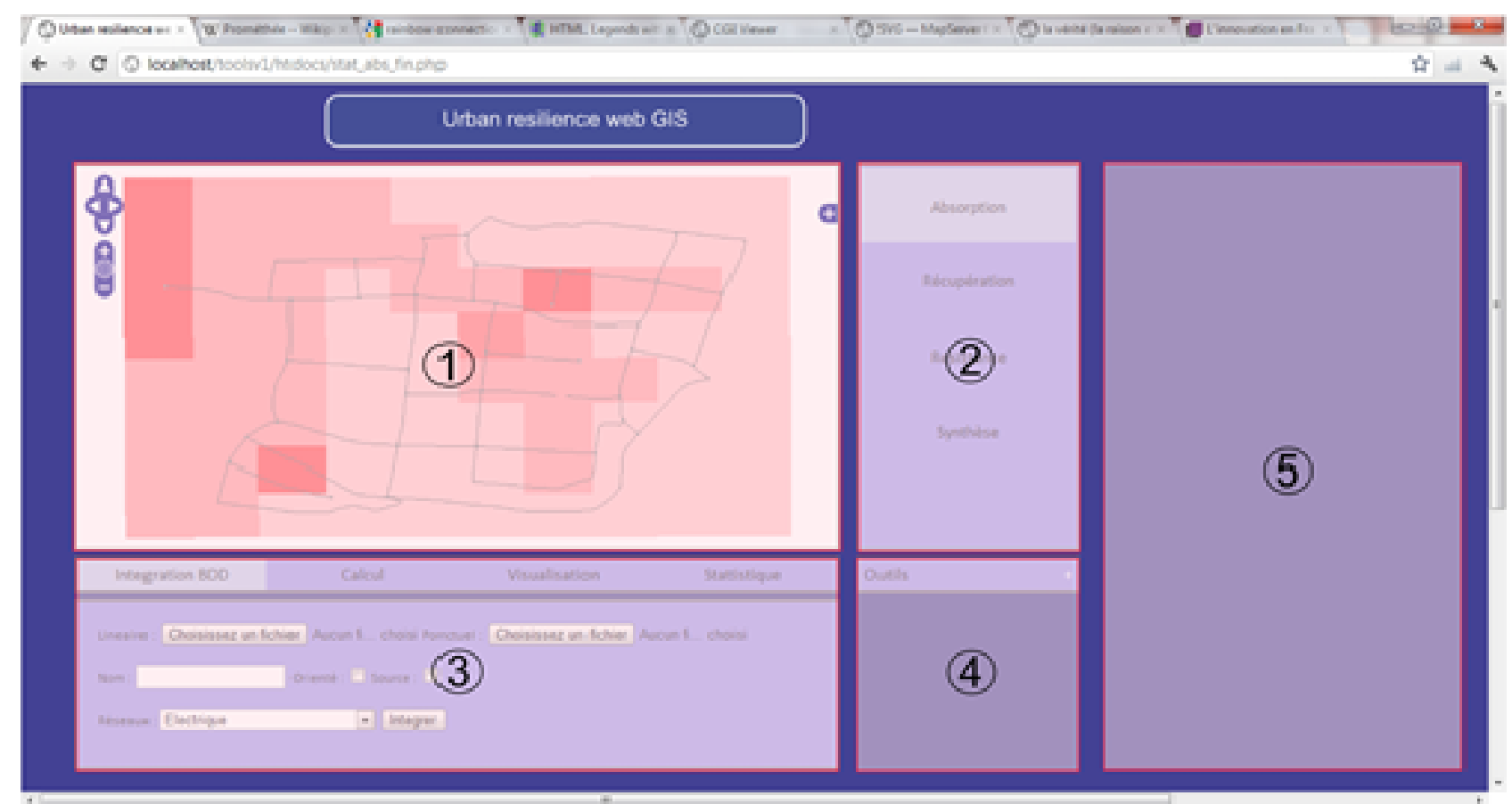

Figure 2. The architecture of the DS3 model is based on four main components (Lhomme et al., 2013): a database storing the data required for calculations (like the network, and major issues); a web server to deliver web content; a map server for mapping application; and a user interface displaying results. Interface is composed by 5 different modules in respect with the methodology and the strategy for assessing networks resiliency: Web-GIS user interface. The map (1) - The menu (2) - Options of each menu (3) Different tools (4) - Information interface (5). Thus, interface menu proposes a four steps analysis: first the absorption capacity analysis; second the resistance capacity analysis; third the recovery capacity analysis; and to conclude a synthesis of the different results with the introduction of critical infrastructures location analysis.

\section{A case study at neighbourhood scale: am sandtorkai / dalmannkai}

Using the DS3 model and considering the three capacities proposed, we proceed to study a particular neighbourhood of Hamburg (Am
Sandtorkai/Dalmannkai). We briefly present the main hydro-geomorphologic characteristics of the specific neighbourhood and then the results of the study.

\subsection{Site description}

The study area is an urban neighbourhood in the northwest of HafenCity, a new district located on the waterfront of the City of Hamburg. HafenCity is one of the most remarkable urban redevelopment schemes on a waterfront worldwide, where the Am Santorkai/Dalmannkai was the first neighbourhood to be completed.

The Am Santorkai/Dalmannkai neighbourhood is characterized by a dense mix of different uses: housing, workplace and leisure uses (shops, cafés, galleries...). Young working singles and families live side by side with empty nesters and seniors: 1500 people live and work in the neighbourhood. Actually, the coexistence of urbanity with village-like life on the waterfront is what gives this neighbourhood its real charm. 
The area is a low-lying island in the river Elbe, intended by several harbour basins; there is an intensive interaction between land and water. Hence, the neighbourhood is located within an area that is subjected to flooding and it is outside the Hamburg's dike line. absorption and/or detention of water; a public open space creates the place for water. Thus, the water speed and the amount of water transmitted between two adjacent urban areas can be reduced. Consequently, these connections contribute to reduce damage in the neighbourhood and so

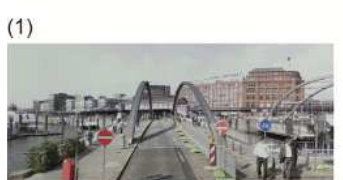

(2)

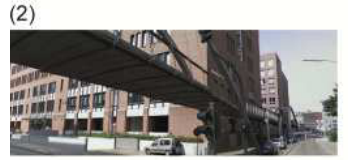

(3)

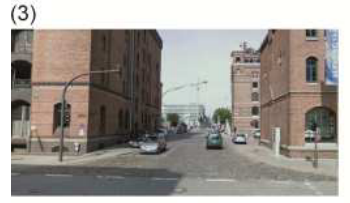

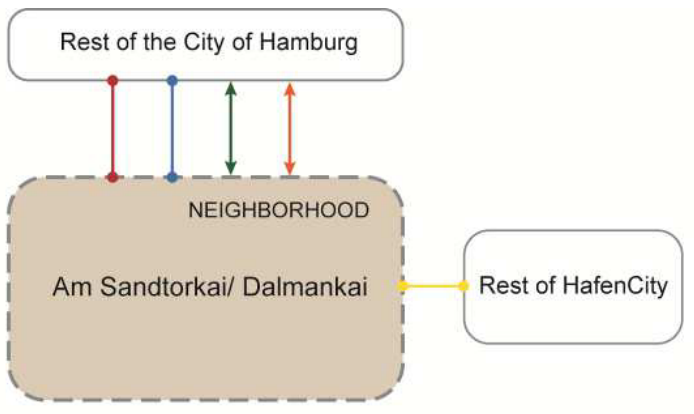

Contact relationships:

$\longrightarrow$ Several transportation connection infrastructures (1) (2) (3) (4)

$\longrightarrow$ Transportation connection infrastructure higher than the reference water level (4) Public open space and green area connection (5)

Flow relationships:

$\longleftrightarrow$ Multiple and public modes of transport (by foot, private transport, bus, bicycle and ferry)

'Soft' modes of transport (by foot, bicycle)

Hide tide together with extreme storm surge in the North Sea produce hazardous flood situation in the neighbourhood and generally in the City of Hamburg. Moreover, last years it has been demonstrated that the area is also affected by pluvial floods. The highest flood in Hamburg was in 1976, when the city was submerged by 6,45 meters of water which is the reference water level (Kluge, 2008).

3.2.1 Connections between the neighbourhood and its environment

Important Significant transportation connections have been identified, concerning infrastructures as well as modes of transport. The neighbourhood is connected with the city centre through four bridges. One of them is flood-secure; it has been laid-out higher than the reference water level and therefore in the case of a storm surge flood, this bridge would be available to rescue vehicles as well as pedestrians. Furthermore, there are multiple modes of transport connecting the neighbourhood with its environment: by foot, bicycle, bus, ferry and private transport. Particularly, there is an extensive network of 'soft' modes of transport that fully integrates the neighbourhood with its adjacent parts.

For example, the fact that a connection infrastructure between the neighbourhood and its environment is higher than the reference water level provides an alternative when the other bridges do not achieve their function and therefore, it contributes to improved absorption capacity. Furthermore, the time required for the neighbourhood recovery can be reduced because it provides accessibility to the neighbourhood even under flooding conditions. Consequently, it is also involved in improving the recovery capacity.

We have also identified green areas and public open spaces that serve as links between the neighbourhood and its adjacent environment. A green area enables the
Figure 3. Connections contributing to improved resilience

to improved resistance capacity. The Figure 3
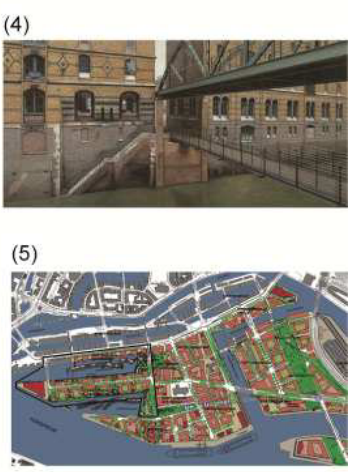
shows connections between the neighbourhood and its environment described.

We now present the urban design strategies which have been selected. Concerning the transportation network, the neighbourhood is innerved by multiple and public modes of transportation interconnected with an extensive network of 'soft' modes of transport through different types of roads: i.e. a main road connects with secondary roads (collector roads, residential streets, foot and path cycles...). Furthermore, some of the roads and/or pathways are being built above the flood-line of reference (at 7,5m above sea level).

For example, an extensive network of 'soft' transportation modes reduces dependency on motorized transports and consequently, on energy resources, to get around the neighbourhood. It reduces the number of motorized transport in the neighbourhood and thus, possible damage they could cause in it. Moreover, it provides an alternative when other transport networks do not achieve their function under flooding conditions. The time required for the neighbourhood recovery can also be reduced because since it does depend on no resource, the network of 'soft' modes of transport will allow immediately displacements in the neighbourhood in order to recover the neighbourhood (critical infrastructures) from possible damage.

Otherwise, some significant land use strategies have also been analysed. The neighbourhood is characterized by an open multidimensional topography: urban spaces extend over different levels. While all buildings and most of roads are built on artificially raised flood-protected bases, around $8 \mathrm{~m}$ above sea level, embankment promenades remain at 4 to $5,5 \mathrm{~m}$. All open public spaces, weather green areas or promenades, are on the waterside and closely interlocked. In these lower areas, occasional flooding will be acceptable. Furthermore, the 
neighbourhood integrates public amenities into ground floors of most of buildings. This open multidimensional topography provides to the neighbourhood the same protection level that compared to the areas of the city surrounded by dikes.

Still concerning land use, the neighbourhood creates a high density of uses with a high proportion of public spaces and low proportion of access roads. Indeed, there is a fine-grained horizontal and vertical mix of variety urban uses.

A high density and mix of urban uses, for example, makes the neighbourhood more autonomous, reducing its dependence on other urban areas. It can reduce damage in the neighbourhood, especially when it is not directly affected by flooding but rather when other areas of the city are flooded. Indeed, a highest level of the neighbourhood autonomy can reduce possible negative impact on its operation (critical infrastructures) caused by other urban areas damaged. Consequently, it contributes to improved resistance capacity.

Finally, regarding energy and water networks, some relevant characteristics have also been selected. On the one hand, the neighbourhood's sewer system consists of dual system for separate draining of sewerage and rainwater. On the other hand, buildings are supplied with remote district heating and heating generated locally: e.g. from decentralized geothermal or solar thermal plants. They complement each other for an effective energy mix.

A dual sewer system allows more water conveyance, reducing possible damage of wastewater pipelines. Consequently, it contributes to improve the resistance capacity. The use of renewable energy sources which do not depend on the remote district heating can reduce damage of neighbourhood's components (critical infrastructures) depending on energy to operate. It can also provide an alternative when remote district heating ceases stops to work and the time required for the neighbourhood recovery (critical infrastructures) can also be reduced.

Buildings are the only type of component that has been considered interesting to be analysed. A relevant characteristic of buildings is their elevation. They stand on artificial bases out of reach the most extreme flooding. Furthermore, their multi-functionality has also been considered. Indeed, the basements inside the buildings provide flood-underground parking for cars. In the case of high water, parking entrances do have to close their flood gates. They are waterproof doors and protect the area behind them from flooding. On the other hand, public amenities (shops, bistros, galleries...) are located into ground floors of most of buildings and apartments and offices are located in the highest levels of buildings. Moreover, the upper part of the buildings (roofs) supports an energy production system. For example, the fact, that the buildings are built higher than the reference water level, provides flood protection and allows urban functions in the buildings, even under flooding conditions. It reduces possible damage in the neighbourhood and also its recovery time. Moreover, when transportation network ceases to work, buildings can be an alternative for people evacuation. Thus, it contributes to improved resistance, absorption and recovery capacities.

\subsection{Results and discussion}

The results described above are synthetized in the figure 4. The different design features identified are classified according the analyses and the capacities. Moreover, two types of contribution are distinguished: we show a clearly positive contribution under any flood conditions with a green arrow and a positive contribution but under certain flood conditions (under certain level of water).

The results suggest that several design features of the neighbourhood are relevant to improved resilience to floods. Particularly, the design features concerning the transportation network, the land use and the buildings seems to highly contribute to incorporate flood resilience in the neighbourhood operation. Even if we present the results separately, according to the three levels of analysis, it is important to highlight the relationships between the results at these different levels. 


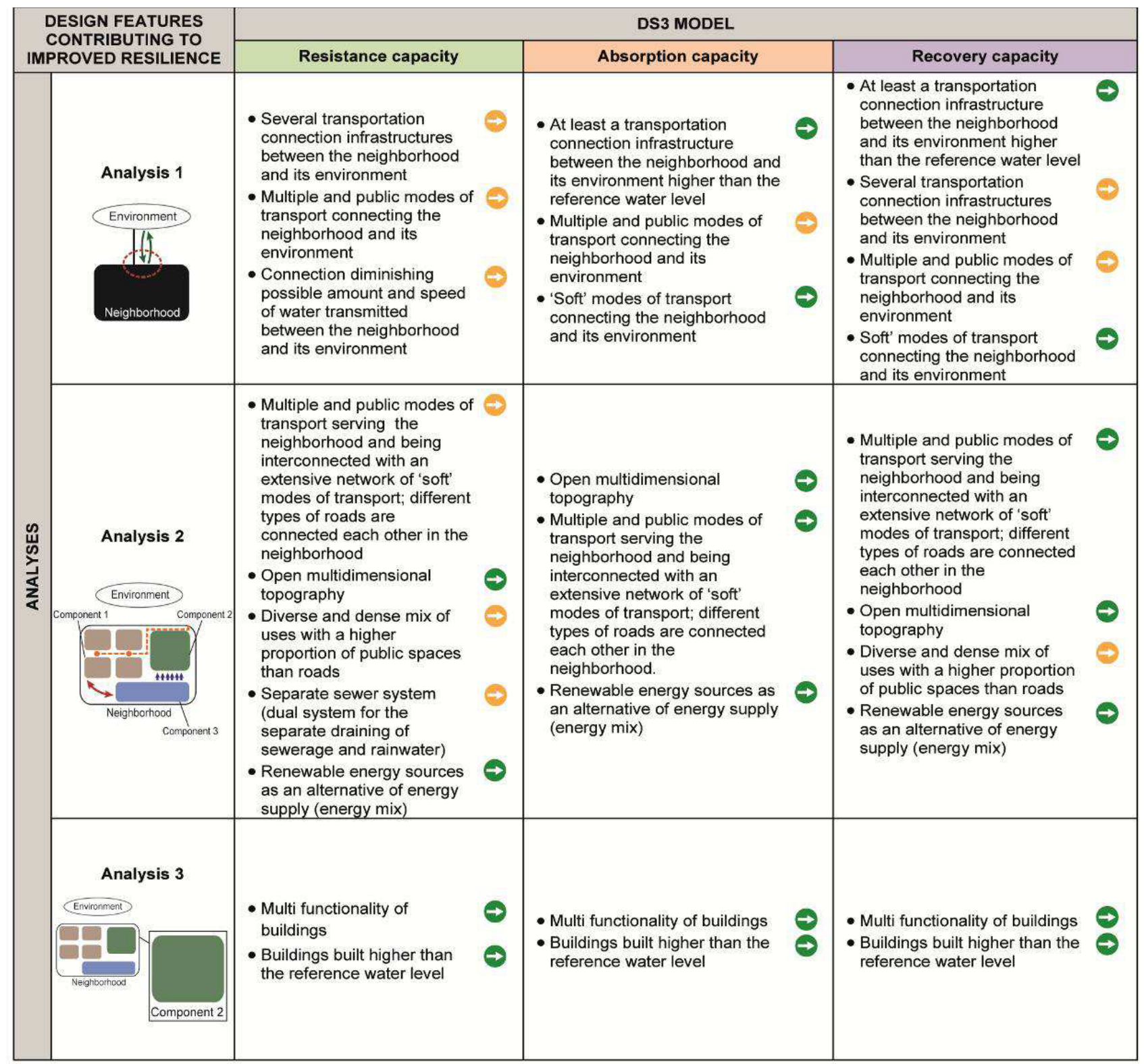

Level of contribution:

$\rightarrow$ A clearly contribution under any conditions

The contribution can be noticed but under certain conditions

Figure 4. Synthesis of the results achieved

In our opinion, there are some main success factors that should be learned from this waterfront neighbourhood. The open multidimensional topography provides to the neighbourhood the same protection level as the other areas of the city surrounded by dikes. Instead of keeping water out, the neighbourhood is designed to allow flood water over or around it in a controlled and predetermined manner. In addition to the contribution of improved resilience, this can help to reduce the maintenance costs associated with protective systems, reduce residual risk and increase awareness. Indeed, the urban design of the neighbourhood creates wider benefits for the sustainable development and the community such as sustainable modes of transport, renewable energy, spaces for outdoor recreation, etc. Furthermore, the multifunctionality and the diversity in the neighbourhood are also relevant factors, which result by design actions

such as the multifunctionality of the buildings, the multiple and public modes of transports serving the neighbourhood and connecting it with its environment, etc.

Finally, we want to emphasize the robustness of the DS3 model in this research. We consider that it is a good conceptual tool to identify what design actions at the neighbourhood scale contribute to improved urban resilience to floods taking into account critical infrastructure interdependencies. Indeed, the application of the DS3 model to this particular neighbourhood, have allowed us to identify several design features involving improved resilience. However, it will be possible to completely validate the model through more experiences like this one. 


\section{Conclusion}

As a preliminary conclusion, we have highlighted the network interdependencies and the propagation of the effect of failures in this linked system. This approach allows evaluating the capacity of resistance of the networks, one of the capacities we consider to design resilient cities. Then, we have used graph theories to assess the redundancy of the urban networks. This approach allows finally assessing another capacity we take into account in our urban resilience assessment method: the capacity of absorption, or the capacity of the city to operate in a degraded mode. We have linked the results of our models with GIS to produce spatial decision support systems to enable the managers of these infrastructures to improve their management to make cities more resilient through the capacity of recovery. Initially, the DS3 model has been developed to studying and assessing the resilience of critical infrastructure (Lhomme et al. 2013). Applying this model for the first time to the neighbourhood scales demonstrates that the model is supplying useful results to analyse ex post the results of a policy of resilience to flood at an operational scale, and ex ante to draw the next steps of an urban process in perspective of achieving resilience to floods.

\section{References}

1. AGO (Australian greenhouse office (2006). Climate change impacts \& risk management - A guide for business and government. Department of Envi-ronment and Heritage, Australian Government.

2. Altman, J.W.(1970). Bahavior and Accident. J. of Safety Research..

3. Amendola, A.(1989). Planning and uncertainties. In proceeding of the 2nd World Bank Workshop on Risk Management and Safety Control. Karlstad, Sweden.

4. Baker, G. H. (2005, April). A vulnerability assessment methodology for critical infrastructure sites. Department of Homeland Security symposium: R\&D partnerships in homeland security. Boston, Massachusetts.

5. Balsells M., Barroca B., Amdal J., Diab Y., Becue V., Serre D., 2013, Application of the DS3 model to the stormwater sewerage system at the neighborhood level, 8è Conférence Internationale Novatech, Lyon, 23 - 27 juin 2013.

6. Boin, A., \& McConnell, A. (2007). Preparing for Critical Infrastructure Breakdowns: The Limits of Crisis Management and the Need for Resilience. Journal of Contingencies and Crisis Management, 15(1), 50-59.

7. Bruijne, M. D., \& Eeten, M. V. (2007). Systems that Should Have Failed: Critical Infrastructure Pro-tection in an Institutionally Fragmented Environ-ment. Journal of Contingencies and Crisis Manage-ment, 15(1).
8. Bruneau, M., S. E. Chang, R. T. Eguchi, G. C. Lee, T. D. O'Rourke, A. M. Reinhorn, M. Shinozuka, K. T. Tierney, W. A. Wallace \& D. Von Winterfeldt. 2003. A framework to quantitatively assess and enhance the seismic resilience of communities. Earthquake Spectra, 19, pp. 733-752.

9. Cancado, Nasciment and Barraud (2011). Flood Risk and Vulnerability_an assessment based on ur-ban network modeling. In proceeding of 12 th Int. Conf. on Urban Drainage, Porto Alegre, Brazil, 11-16 Sept. 2011.

10. Clarke, K. R. \& R. M. Warwick. 1998. Quantifying structural redundancy in ecological communities. Oecologia, 113, 278-289.

11. CSA (Canadian Standards Association (1991), Risk Analysis Requirements and Guidelines, CAN/CSA Q634-M9.

12. DSB (1994). A guide to risk and vulnerability as-sessment in the municipality. Norwegian Directorate for Civil Protection and Emergency Planning.

13. Eusgeld, I., Kröger, W., Sansavini, G., Schläpfer, M., \& Zio, E. (2009). The role of network theory and object-oriented modeling within a framework for the vulnerability analysis of critical infrastructures. Reli-ability Engineering \& System Safety, 94(5), 954-963.

14. Ezell, B. C. (2007). Infrastructure Vulnerability Assessment Model (I-VAM). Risk Analysis, 27(3), 571-83.

15. Haimes, Y. Y., \& Longstaff, T. (2002). The role of risk analysis in the protection of critical infrastruc-tures against terrorism. Risk Analysis, 22(3), 439-44.

16. Holling, C. S. (1973) Resilience and stability of ecological systems. Annual Review of ecology and systematics, vol. 4, $23 \mathrm{p}$.

17. Kluge K. (2012). Floods in Hamburg. http://www.rigapretpludiem.lv/ (accessed 2 March 2013)

18. LaPorte, T. R. (2007). Critical Infrastructure in the Face of a Predatory Future: Preparing for Unto-ward Surprise. Journal of Contingencies and Crisis Management, 15(1), 60-64.

19. Lhomme S., Serre D., Diab Y., Laganier R., A Methodology to Produce Interdependent Networks Disturbance Scenarios, Vulnerability, Uncertainty, and Risk: Analysis, Modeling, and Management Proceedings of the ICVRAM 2011 and ISUMA 2011 Conferences, pp. 724-731, 2011, Hyattsville, MD, USA

20. Lhomme S., Serre D., Diab Y., Laganier R., 2013, Assessing the resilience of the urban networks: a preliminary step towards more flood resilient cities, Nat. Hazards Earth Syst. Sci., 13, pp. 221-230. www.nat-hazards-earth-systsci.net/13/221/2013/ doi:10.5194/nhess-13-2212013.

21. Matisziw, T. C., Murray, A. T., \& Grubesic, T. H. (2008). Exploring the vulnerability of 
network infra-structure to disruption. The Annals of Regional Sci-ence, 43(2), 307-321.

22. McNally, R. K., Lee, S.-W., Yavagal, D., \& Xiang, W.-N. (2007). Learning the critical infrastruc-ture interdependencies through an ontology-based information system. Environment and Planning B: Planning and Design, 34(6).

23. Nie, L., Heilemann, K. Hafskjold, L.S., Sægrov, S., Johannessen, B.G. (2009). Adapting community to flood risk and vulnerability caused by climate change. In: E. Pasch, N. Evelpidou, C. Zevenbergen, R. Ashley, S. Garvin (eds.): Int. Con. of European and Global Communities combine forces on Flood Resilient Cities, Paris, France, 26-27th November 2009.

24. Nie, L., Li, P., Nilsen, V. (2012). Modelling climate change impacts on urban stormwater and adap-tation efficiency (submitted), the 9th Joint IWA/IAHR Conf. on Urban Drainage Modelling.

25. NTS (Norwegian Technology Standards Institution) (1998). Risk and Emergency Preparedness Analysis (Z-013). Rev. 1, March 1998, NORSOK standard.pp.5

26. Ouyang, M., Hong, L., Mao, Z.-jun, Yu, M.-hui, \& Qi, F. (2009). Simulation Modelling Practice and Theory A methodological approach to analyze vul-nerability of interdependent infrastructures. Simula-tion Modelling Practice and Theory, 17(5), 817-828.

27. Parks, R. C., \& Rogers, E. (2008). Vulnerability assessment for critical infrastructure control systems. IEEE Security \& Privacy, 6(6), 37-43.

28. Pederson P., Dudenhoeffer D., Hartley S., Permann M. (2005) Critical Infrastructure Interdepend-ency Modeling: A Survey of U.S. and International Research.

29. Rinaldi, S. M. (2004). Modeling and simulating critical infrastructures and their interdependencies. 37th Annual Hawaii International Conference on System Sciences, 2004. Proceedings of the, 00(C), $8 \mathrm{pp}$. Ieee. doi:10.1109/HICSS.2004.1265180

30. Serre D. (2011) Flood resilient city - Assessment methods and tools. Thesis for the obtention of the Habilitation to Lead Researches, Université Paris-Est, 173 p.

31. Serre D., Barroca B., Laganier R. 2013, Resilience and Urban Risk Management, CRC Press Balkema, Taylor \& Francis Group, ISBN 978-0-415-62147-2.

32. Vatn J. (2007). Description of tool for Identification and Estimation of Risk-related Critical Infra-structure (InfraRisk). Department of Production and Quality Engineering, Norwegian University of Sci-ence and Technology.

33. Winkler, J., Dueñas-Osorio, L., Stein, R., \& Subramanian, D. (2010). Performance assessment of topologically diverse power systems subjected to hurricane events.
Reliability Engineering \& System Safety, 95(4), 323-336.

34. Zhou, Q., Halsnæs, K., Arnbjerg-Nielsen, K.(2011) et al, 2009. Economic assessment of cli-mate adaptation options for urban drainage in Oden-se, Denmark. 